\title{
Complete genome sequence of a plant associated bacterium Bacillus amyloliquefaciens subsp. plantarum UCMB5033
}

\author{
Adnan Niazi ${ }^{1 *}$, Shahid Manzoor ${ }^{1,3}$, Sarosh Bejai $^{2}$, Johan Meijer ${ }^{2}$, Erik Bongcam-Rudloff ${ }^{1}$ \\ ${ }^{1}$ Department of Animal Breeding and Genetics, SLU Global Bioinformatics Centre, Swedish \\ University of Ag ricultural Sciences, Uppsala, Sweden. \\ ${ }^{2}$ Department of Plant Biology and Forest Genetics, Uppsala Biocenter, Swedish University \\ of Agricultural Sciences and Linnéan Center for Plant Biology, Uppsala, Sweden \\ ${ }^{3}$ University of the Punjab, Lahore, Pakistan. \\ *Correspondence: Adnan Niazi (adnan.niazi@slu.se)
}

Keywords: Bacillus amyloliquefaciens, biocontrol, rhizobacteria, priming, stress

Bacillus amyloliquefaciens subsp. plantarum UCMB5033 is of special interest for its ability to promote host plant growth through production of stimulating compounds and suppression of soil borne pathogens by synthesizing antibacterial and antifungal metabolites or priming plant defense as induced systemic resistance. The genome of $B$. amyloliquefaciens UCMB5033 comprises a 4,071,167 bp long circular chromosome that consists of 3,912 protein-coding genes, 86 tRNA genes and 10 rRNA operons.

Abbreviations: UCM- Ukrainian Collection of Microorganisms, ENA- European Nucleotide Archive, PGPB- Plant growth promoting bacterium

\section{Introduction}

Bacillus amyloliquefaciens is a plant-associated species belonging to the family Bacillaceae. The members of the genus Bacillus are ubiquitous in nature and include biologically and ecologically diverse species, ranging from those beneficial for economically important plants, to pathogenic species that are harmful to humans. $B$. amyloliquefaciens UCMB5033 is a plant growth promoting bacterium (PGPB) that was isolated from a cotton plant [1]. Studies have shown that $B$. amyloliquefaciens UCMB5033 is an important tool for studies of plant-bacteria associations, has potential to confer protection against soil borne pathogens, and to stimulate growth of oilseed rape (Brassica napus) [2]. Such traits make UCMB5033 an important tool for studies of plant-bacteria associations and production of compounds that directly or indirectly promote plant growth or stress tolerance. Here we present a description of the complete genome sequencing of $B$. amyloliquefaciens UCMB5033 and its an notation.

\section{Classification and features}

Strain UCMB5033 was identified as a member of the $B$. amyloliquefaciensgroup based on phenotypic analysis [1]. The comparison of $16 \mathrm{~S}$ rRNA gene sequences with the most recent databases from GenBank using NCBI BLAST [3] under default settings showed that B. amyloliquefaciens UCMB5033 shares 99\% identity with many Bacillusspecies including Bacillus atrophaeus (CP002207.1) and Bacillus subtilis subsp. spizizenii str. W23 (CP002183.1). Figure 1 shows the phylogenetic relationship of B. amyloliquefaciens UCMB5033 with other species within the genus Bacillus. The tree highlights the close relationship of UCMB5033 with the B. amyloliquefaciens subsp. plantarum type strain FZB42. The other $B$. amyloliquefacienstype strain DSM $7^{\mathrm{T}}$ representing subsp. amyloliquefaciens, displayed less taxonomic relatedness and strain UCMB5033 can thus be regarded as belonging to the subsp. plantarum also in line with its plant associated characteristics [7]. 


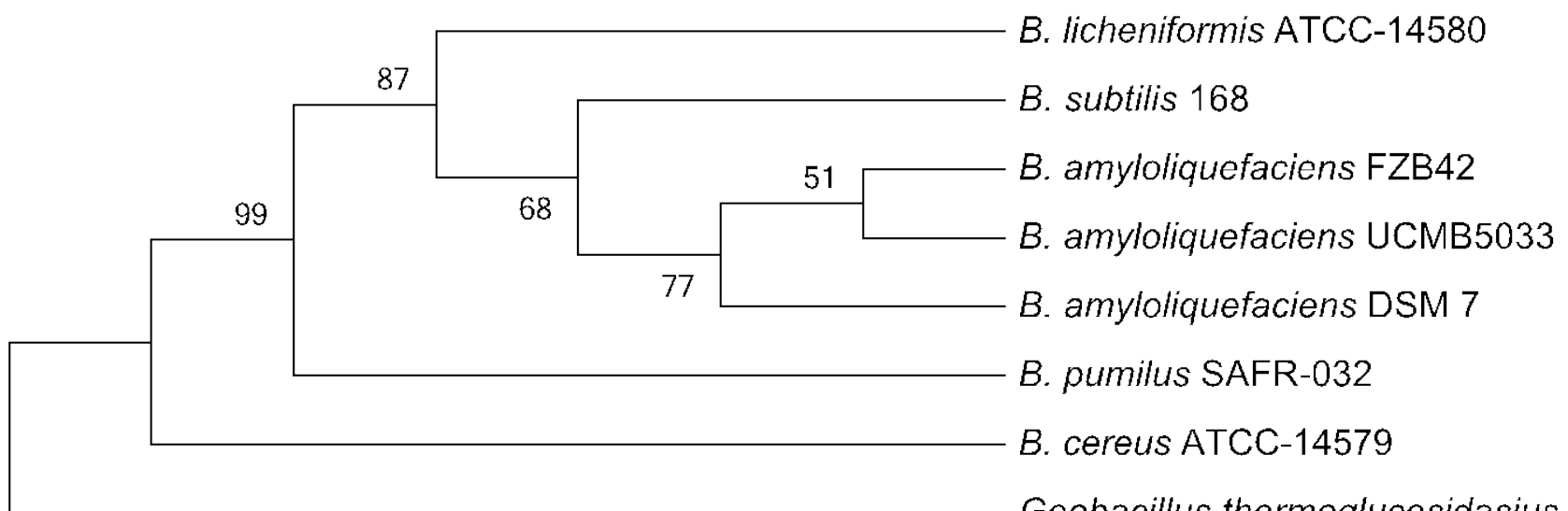

Figure 1. Phylogenetic tree showing the position of $B$. amyloliquefaciens UCMB5033 in relation to other species within the genus Bacillus. The tree is based on 16S rRNA gene sequences alig ned with MUSCLE [4] was inferred under maximum likelihood criterion using MEGA5 [5] and rooted with Geobacillus thermog/ucosidasius (a member of the family Bacillaceae). The numbers above the branches are support values from 1,000 bootstrap replicates if larger than 50\% [6].

\section{Morphology and physiology}

B. amyloliquefaciens UCMB5033 is a Grampositive, rod shaped, motile, spore forming, aerobic, and mesophilic microorganism (Table 1). Strain UCMB5033 is approximately $0.8 \mu \mathrm{m}$ wide and $2 \mu \mathrm{m}$ long that can grow on Luria Broth (LB) and potato dextrose agar (PDA) between $20{ }^{\circ} \mathrm{C}$ and $37{ }^{\circ} \mathrm{C}$ within the $\mathrm{pH}$ range $4-8 . \quad B$. amyloliquefaciens UCMB5033 has properties as a plant growth promoting rhizobacterium (PGPR) [2]. The ability to catabolize plant derived compounds, resistance to metals and drugs; root colonization and biosynthesis of metabolites presumably give $B$. amyloliquefaciens UCMB5033 an advantage in developing a symbiotic relationship with plants in competition with other microorganims in the soil microbiota.

\section{Genome assembly and annotation}

\section{Growth conditions and DNA isolation}

B. amyloliquefaciens UCMB5033 was grown in LB medium at $28^{\circ} \mathrm{C}$ for 12 hours (cells were in the early stationary phase). The genomic DNA was isolated using a QIAmp DNA mini kit (Qiagen).

\section{Genome sequencing}

B. amyloliquefaciens UCMB5033, originally isolated from cotton plant, was selected for sequencing on the basis of its ability to promote rapeseed growth and inhibit soil borne pathogens. Genome sequencing of B. amyloliquefaciens UCMB5033 using Illumina multiplex technology and Ion Torrent PGM systems was performed by Science for Life Laboratory (SciLifeLab) at Uppsala University. The genome project is deposited in the Genomes On Line Databases [24] and the complete genome sequence is deposited in the ENA database under accession number HG328253. A summary of the project information is shown in Table 2 and its association with MIGS identifiers.

\section{Genome assembly}

The genome of $B$. amyloliquefaciens UCMB5033 was assembled using 21,919,534 Illumina pairedend reads (75bp) and 1,922,725 single-end reads (Ion Torrent). The chromosome of size 4,071,167 bp was assembled by providing paired-end reads to MIRA v.3.4 [25] for reference-guided assembly using the available genome sequence of $B$. amyloliquefaciens UCMB5036 (accession no. HF563562) [26]. Whereas, single-end reads were assembled with Newbler v.2.8 by a de novo assembly method. Both forms of assemblies were compared after alignment to identify indels and cover gap regions using Mauve genome alignment software [27]. 
Table 1. Classification and general features of $B$. amyloliquefaciens subsp. plantarum UCMB5033 according to the MIGS recommendation [8].

\begin{tabular}{|c|c|c|c|}
\hline MIGS ID & Property & Term & 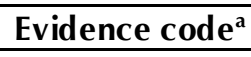 \\
\hline & \multirow{9}{*}{ Classification } & Domain Bacteria & TAS [9] \\
\hline & & Phylum Firmicutes & TAS [10-12] \\
\hline & & Class Bacilli & \\
\hline & & Order Bacillales & 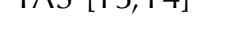 \\
\hline & & & TAS $[15,16]$ \\
\hline & & Family Bacillaceae & TAS $[15,17]$ \\
\hline & & Genus Bacillus & TAS $[151819]$ \\
\hline & & Species Bacillus amyloliquefaciens & \\
\hline & & Strain UCMB5033 & 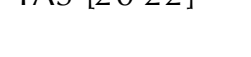 \\
\hline & Gram stain & Positive & IDA \\
\hline & Cell shape & Rod-shaped & IDA \\
\hline & Motility & Motile & IDA \\
\hline & Sporulation & Sporulating & IDA \\
\hline & Temperature range & Mesophilic & IDA \\
\hline & Optimum temperature & $28^{\circ} \mathrm{C}$ & IDA \\
\hline & Carbon source & $\begin{array}{l}\text { Glucose, fructose, trehalose, mannitol, sucrose, } \\
\text { arabinose, raffinose }\end{array}$ & IDA \\
\hline & Energy source & -- & \\
\hline & Terminal electron receptor & -- & \\
\hline MIGS-6 & Habitat & Soil, Host (Plant) & IDA \\
\hline MIGS-6. 3 & Salinity & up to $12 \% \mathrm{w} / \mathrm{v}$ & TAS $[20,21]$ \\
\hline MIGS-22 & Oxygen & Aerobic & IDA \\
\hline MIGS-15 & Biotic relationship & Symbiotic (beneficial) & TAS [2] \\
\hline MIGS-14 & Pathog enicity & None & NAS \\
\hline MIGS-4 & Geographic location & Tajikistan & \\
\hline MIGS-5 & Sample collection time & -- & \\
\hline MIGS-4.1 & Latitude & -- & \\
\hline MIGS-4.2 & Long itude & -- & \\
\hline MIGS-4.3 & Depth & -- & \\
\hline MIGS-4.4 & Altitude & -- & \\
\hline
\end{tabular}

a) Evidence codes - IDA: Inferred from Direct Assay; TAS: Traceable Author Statement (i.e., a direct report exists in the literature); NAS: Non-traceable Author Statement (i.e., not directly observed for the living, isolated sample, but based on a generally accepted property for the species, or anecdotal evidence). These evidence codes are from the Gene Ontology project [23]. 


\section{Genome annotation}

The genome sequence was annotated using a combination of several annotation tools via the Magnifying Genome (MaGe) Annotation Platform [28]. Genes were identified using Prodigal [29] and AMIGene [30] as part of the MaGe genome annotation pipeline followed by manual curation. Putative functional annotation of the predicted protein coding genes was done automatically by MaGe after BlastP similarity searches against the Uniprot and Trembl, TIGR-Fam, Pfam, PRIAM, COG and InterPro databases. The tRNAScanSE tool [31] was used to find tRNA genes. Ribosomal RNA genes were identified using RNAmmer tool [32].

\section{Genome properties}

The B. amyloliquefaciens UCMB5033 genome consists of a circular chromosome of size 4,071,168 bp. The genome having $\mathrm{G}+\mathrm{C}$ content of $46.19 \%$ were predicted to contain 4,095 predicted ORFs including 10 copies each of 16S, 23S, and 5S rRNA; 86 tRNA genes, and 3,912 protein-coding sequences with the coding density of $87.51 \%$ (Figure 2). The majority of protein coding genes (81\%) was assigned putative functions while those remaining were annotated as hypothetical or conserved hypothetical proteins (Table 3). The distribution into COG functional categories is presented in Table 4.

Table 2. Genome sequencing Project information

\begin{tabular}{lll}
\hline MIGS ID & Property & Term \\
\hline MIGS-31 & Finishing quality & Finished \\
MIGS-28 & Libraries used & Illumina PE (75bp reads, insert size of 230bp), lonTorrent sing le end reads \\
MIGS-29 & Sequencing platforms & Illumina GAii, lonTorrent PGM Systems \\
MIGS-31.2 & Fold coverage & 140× Illumina; 35× lonTorrent \\
MIGS-30 & Assemblers & MIRA 3.4 and Newbler 2.8 \\
MIGS-32 & Gene calling method & PRODIGAL, AMIGene \\
& ENA Project ID & PRJEB3961 \\
& Date of Release & September 8, 2013 \\
& INSDC ID & HG328253 \\
& GOLD ID & Gc0053646 \\
& Project relevance & Biocontrol, Agriculture \\
\hline
\end{tabular}

Table 3. Nucleotide content and gene count levels of the genome

\begin{tabular}{lrr}
\hline Attribute & Value & \% $^{\text {of total }} \mathbf{~}^{\mathbf{a}}$ \\
\hline Genome size (bp) & $4,071,168$ & 100 \\
DNA cding region (bp) & $3,565,936$ & 87.5 \\
DNA G+C content (bp) & $1,880,879$ & 46.1 \\
Total number of genes ${ }^{\mathrm{b}}$ & 4095 & $\mathrm{n} / \mathrm{a}$ \\
RNA genes & 116 & $\mathrm{n} / \mathrm{a}$ \\
rRNA operons & 10 & $\mathrm{n} / \mathrm{a}$ \\
Protein-coding genes & 3912 & 100 \\
CDSs with predicted functions & 3170 & 81 \\
Uncharacterized/Hypothetical genes & 742 & 18.1 \\
CDSs assigned to COGs & 3506 & 89.6 \\
CDSs with signal peptides & 302 & 7.7 \\
CDSs with transmembrane helices & 1012 & 25.8 \\
\hline
\end{tabular}

a) The total is based on either the size of the genome in base pairs or the total number of protein coding genes in the annotated genome.

b) Also includes 36 pseudogenes and 66 non-coding RNA. 


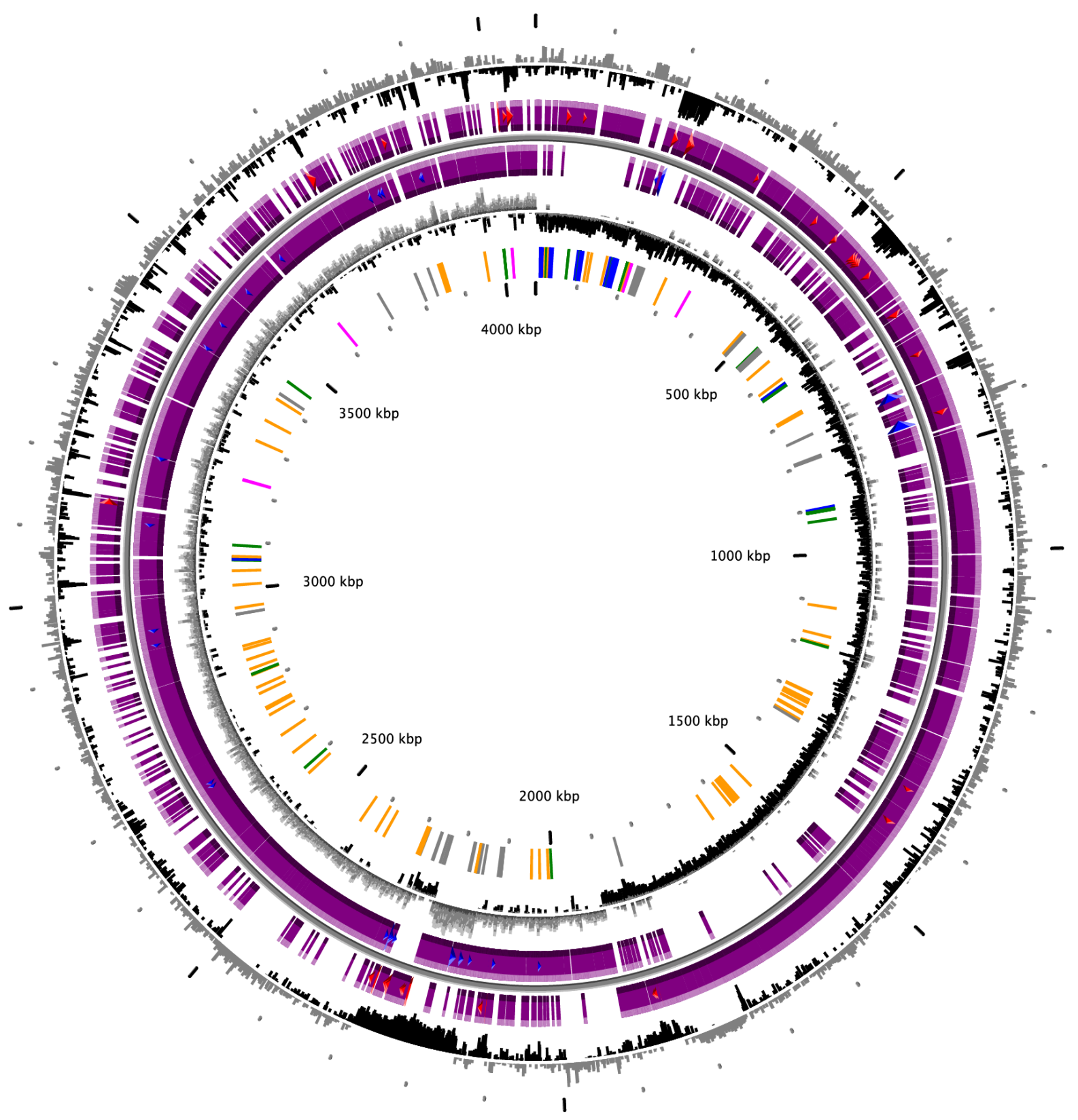

Figure 2. Graphical circular map of the $B$. amyloliquefaciens UCMB5033 genome. From outer to inner circle: (1) GC percent deviation (GC window - mean GC) in a 1000-bp window. (2) Predicted CDSs transcribed in the clockwise direction. (3) Predicted CDSs transcribed in the counter-clockwise direction. Red and blue genes displayed in (2) and (3) are MaGe validated annotations and automatic annotations, respectively. (4) GC skew (G+C/G-C) in a 1,000-bp window. (5) rRNA (blue), tRNA (green), non-coding_RNA (orange), Transposable elements (pink) and pseudog enes (g rey). 
Table 4. Number of genes associated with the 25 general COG functional categ ories

\begin{tabular}{|c|c|c|c|}
\hline Code & Value & $\%$ age $^{\mathrm{a}}$ & Description \\
\hline$J$ & 159 & 4.06 & Translation \\
\hline A & 1 & 0.025 & RNA processing and modification \\
\hline K & 287 & 7.33 & Transcription \\
\hline $\mathrm{L}$ & 141 & 10.58 & Replication, recombination and repair \\
\hline B & 1 & 0.025 & Chromatin structure and dynamics \\
\hline D & 38 & 0.97 & Cell cycle control, mitosis and meiosis \\
\hline Y & 0 & 0.00 & Nuclear structure \\
\hline V & 50 & 1.27 & Defense mechanisms \\
\hline $\mathrm{T}$ & 167 & 4.26 & Signal transduction mechanisms \\
\hline M & 196 & 5.01 & Cell wall/membrane biog enesis \\
\hline $\mathrm{N}$ & 63 & 1.61 & Cell motility \\
\hline Z & 0 & 0 & Cytoskeleton \\
\hline W & 0 & 0 & Extracellular structures \\
\hline$U$ & 54 & 1.38 & Intracellular trafficking and secretion \\
\hline $\mathrm{O}$ & 98 & 2.5 & Posttranslational modification, protein turnover, chaperones \\
\hline $\mathrm{C}$ & 181 & 4.62 & Energy production and conversion \\
\hline G & 270 & 6.9 & Carbohydrate transport and metabolism \\
\hline $\mathrm{E}$ & 313 & 8 & Amino acid transport and metabolism \\
\hline $\mathrm{F}$ & 98 & 2.5 & Nucleotide transport and metabolism \\
\hline $\mathrm{H}$ & 145 & 3.7 & Coenzyme transport and metabolism \\
\hline I & 169 & 4.32 & Lipid transport and metabolism \\
\hline$P$ & 167 & 4.26 & Inorg anic ion transport and metabolism \\
\hline Q & 163 & 4.16 & Secondary metabolites biosynthesis, transport and catabolism \\
\hline $\mathrm{R}$ & 426 & 10.88 & General function prediction only \\
\hline S & 319 & 8.15 & Function unknown \\
\hline- & 406 & 10.37 & Not in COGs \\
\hline
\end{tabular}

a) The total is based on the total number of protein coding genes in the annotated genome.

\section{Conclusion}

Comparative genome analysis might reveal mechanisms by which UCMB5033 mediates plant protection and growth promotion, will further enable the investigations of the biochemical and regula-

\section{Acknowledgement}

This work was supported by the grants from Swedish Research Council for Environment, Agricultural Sciences and Spatial Planning (FORMAS) and the Higher Education Commission (HEC), Pakistan. The SNP\&SEQ Technology Platform and Uppsala Genome Center performed sequencing supported by Science for Life La- tory mechanisms behind the symbiotic relationship, and will shed light on the activity of PGPR in different environments.

boratory (Uppsala), a national infrastructure supported by the Swedish Research Council (VR-RFI) and the Knut and Alice Wallenberg Foundation. The Bioinformatics Infrastructure for the Life Sciences (BILS) supported the SGBC bioinformatics platform at SLU. 


\section{References}

1. Reva ON, Dixelius C, Meijer J, Priest FG. Taxonomic characterization and plant colonizing abilities of some bacteria related to Bacillus amyloliquefaciens and Bacillus subtilis. FEMS Microbiol Ecol 2004; 48:249-259. PubMed http://dx.doi.org/10.1016/j.femsec.2004.02.003

2. Danielsson J, Reva ON, Meijer J. Protection of oilseed rape (Brassica napus) toward fungal pathog ens by strains of plant-associated Bacillus amyloliquefaciens. Microb Ecol 2007; 54:134140. PubMed http://dx.doi.org/10.1007/s00248$\underline{006-9181-2}$

3. Altschul SF, Madden TL, Schäffer AA, Zhang J, Zhang Z, Miller W, Lipman DJ. Gapped BLAST and PSI-BLAST: a new generation of protein database search prog rams. Nucleic Acids Res 1997; 25:3389-3402. PubMed http://dx.doi.org/10.1093/nar/25.17.3389

4. Edgar RC. MUSCLE: multiple sequence alignment with high accuracy and high throug hput. Nucleic Acids Res 2004; 32:1792-1 797. PubMed http://dx.doi.org/10.1093/nar/gkh340

5. Tamura K, Peterson D, Peterson N, Stecher G, Nei M, Kumar S. MEGA5: molecular evolutionary genetics analysis using maximum likelihood, evolutionary distance, and maximum parsimony methods. Mol Biol Evol 2011; 28:2731-2739. PubMed http://dx.doi.org/10.1093/molbev/msr121

6. Pattengale ND, Alipour M, Bininda-Emonds ORP, Moret BME, Stamatakis A. How many bootstrap replicates are necessary? J Comput Biol 2010;

17:337-354. PubMed http://dx.doi.org/10.1089/cmb.2009.0179

7. Borriss R, Chen XH, Rueckert C, Blom J, Becker A, Baumg arth B, Fan B, Pukall R, Schumann P, Spröer C, et al. Relationship of Bacillus amyloliquefaciensclades associated with strains DSM 7T and FZB42T: a proposal for Bacillus amyloliquefaciens subsp. amyloliquefaciens subsp. nov. and Bacillus amyloliquefaciens subsp. plantarum subsp. nov. based on complete genome sequence comparisons. Int J Syst Evol Microbiol 2011; 61:1786-1801. PubMed http://dx.doi.org/10.1099/ijs.0.023267-0

8. Field D, Garrity G, Gray T, Morrison N, Seleng ut J, Sterk P, Tatusova T, Thomson N, Allen MJ, Ang iuoli SV, et al. The minimum information about a genome sequence (MIGS) specification. Nat Biotechnol 2008; 26:541-547. PubMed http://dx.doi.org/10.1038/nbt1360
9. Woese CR, Kandler O, Wheelis ML. Towards a natural system of organisms: proposal for the domains Archaea, Bacteria, and Eucarya. Proc Natl Acad Sci USA 1990; 87:457 6-4579. PubMed http://dx.doi.org/10.1073/pnas.87.12.4576

10. Gibbons NE, Murray RGE. Proposals Concerning the Higher Taxa of Bacteria. Int I Syst Bacteriol 1978; 28:1-6. http://dx.doi.org/10.1099/00207713-28-1-1

11. Garrity GM, Holt JG. The Road Map to the Manual. In: Garrity GM, Boone DR, Castenholz RW (eds), Bergey's Manual of Systematic Bacteriology, Second Edition, Volume 1, Springer, New York, 2001, p. 119-169.

12. Murray RGE. The Higher Taxa, or, a Place for Everything ...? In: Holt JG (ed), Bergey's Manual of Systematic Bacteriology, First Edition, Volume 1, The Williams and Wilkins Co., Baltimore, 1984, p. 31-34.

13. List of new names and new combinations previously effectively, but not validly, published. List no. 132. Int / Syst Evol Microbiol 2010; 60:469472. http://dx.doi.org/10.1099/ijs.0.022855-0

14. Ludwig W, Schleifer KH, Whitman WB. Class I. Bacilliclass nov. In: De Vos P, Garrity G, Jones D, Krieg NR, Ludwig W, Rainey FA, Schleifer KH, Whitman WB (eds), Bergey's Manual of Systematic Bacteriology, Second Edition, Volume 3, Springer-Verlag, New York, 2009, p. 19-20.

15. Skerman VBD, McGowan V, Sneath PHA. Approved Lists of Bacterial Names. Int J Syst Bacteriol 1980; 30:225-420. http://dx.doi.org/10.1099/00207713-30-1-225

16. Prévot AR. In: Hauderoy P, Ehring er G, Guillot G, Mag rou. J., Prévot AR, Rosset D, Urbain A (eds), Dictionnaire des Bactéries Pathogènes, Second Edition, Masson et Cie, Paris, 1953, p. 1-692.

17. Fischer A. Untersuchung en über bakterien. Jahrbücher für Wissenschaftliche Botanik 1895; 27:1-163.

18. Cohn F. Untersuchung en über Bakterien. Beitr Biol Pflanz 1872; 1:127-224.

19. Gibson T, Gordon RE. Genus I. Bacillus Cohn 1872, 174; Nom. gen. cons. Nomencl. Comm. Intern. Soc. Microbiol. 1937, 28; Opin. A. Jud. Comm. 1955, 39. In: Buchanan RE, Gibbons NE (eds), Bergey's Manual of Determinative Bacteriology, Eighth Edition, The Williams and Wilkins Co., Baltimore, 1974, p. 529-550. 
20. Priest FG, Goodfellow M, Shute LA, Berkeley RCW. Bacillus amyloliquefaciens sp. nov., nom. rev. Int J Syst Bacteriol 1987; 37:69-71. http://dx.doi.org/10.1099/00207713-37-1-69

21. Wang LT, Lee FL, Tai CJ, Kuo HP. Bacillus velezensis is a later heterotypic synonym of Bacillus amyloliquefaciens. Int I Syst Evol Microbiol 2008; 58:671-675. PubMed http://dx.doi.org/10.1099/ijs.0.65191-0

22. Studies on the production of bacterial amylase. I. Isolation of bacteria secreting potent amylase and their distribution. Nippon Noge ikagaku Ka ishi 1943; 19:487-503. http://dx.doi.org/10.1271/nogeikagaku1924.19.7 $\underline{487}$

23. Ashburner M, Ball CA, Blake JA, Botstein D, Butler H, Cherry JM, Davis AP, Dolinski K, Dwight SS, Eppig JT, et al. Gene ontology: tool for the unification of biology. The Gene Ontology Consortium. Nat Genet 2000; 25:25-29. PubMed http://dx.doi.org/10.1038/75556

24. Pagani I, Liolios K, Jansson J, Chen IM, Smirnova T, Nosrat B, Markowitz VM, Kyrpides NC. The Genomes OnLine Database (GOLD) v.4: status of genomic and metagenomic projects and their associated metadata. Nucleic Acids Res 2012; 40:D571-D579. PubMed http://dx.doi.org/10.1093/nar/gkr1100

25. Chevreux B, Wetter T, Suhai S. Genome Sequence Assembly Using Trace Signals and Additional Sequence Information. German Conference on Bioinformatics 1999. Available at: http://citeseerx.ist.psu.edu/viewdoc/summary?doi $=10.1 .1 .23 .7465$.
26. Manzoor S, Niazi A, Bejai S, Meijer J, BongcamRudloff E. Genome Sequence of a PlantAssociated Bacterium, Bacillus amyloliquefaciens Strain UCMB5036. Genome Announc. 2013;1.

27. Darling AE, Mau B, Perna NT. prog ressiveMauve: multiple genome alig nment with gene gain, loss and rearrangement. PLOS ONE 2010; 5:e11147. $\underline{\text { PubMed }}$ http://dx.doi.org/10.1371/journal.pone.0011147

28. Vallenet D, Engelen S, Mornico D, Cruveiller S, Fleury L, Lajus A, Rouy Z, Roche D, Salvignol G, Scarpelli C, Médig ue C. MicroScope: a platform for microbial genome annotation and comparative genomics. Database (Oxford) 2009;

2009:bap021. PubMed http://dx.doi.org/10.1093/database/bap021

29. Hyatt D, Chen GL, LoCascio PF, Land ML, Larimer FW, Hauser LJ. Prodigal: prokaryotic gene recognition and translation initiation site identification. BMC Bioinformatics 2010; 11:119. PubMed http://dx.doi.org/10.1186/1471-2105-11-119

30. Bocs S, Cruveiller S, Vallenet D, Nuel G, Médig ue C. AMIGene: Annotation of Microbial Genes. Nucleic Acids Res 2003; 31:372 3-3726. PubMed http://dx.doi.org/10.1093/nar/g kg 590

31. Lowe TM, Eddy SR. tRNAscan-SE: a prog ram for improved detection of transfer RNA genes in genomic sequence. Nucleic Acids Res 1997;

25:95 5-964. PubMed http://dx.doi.org/10.1093/nar/25.5.0955

32. Lagesen K, Hallin P, Rødland EA, Stærfeldt HH, Rognes T, Ussery DW. RNAmmer: consistent and rapid annotation of ribosomal RNA genes. Nucleic Acids Res 2007; 35:3100-3108. PubMed http://dx.doi.org/10.1093/nar/gkm160 